\title{
Development and presentation of the first design process model for sports equipment design
}

\author{
Nicky Wilson ${ }^{1} \cdot$ Avril Thomson $^{1} \cdot$ Philip Riches $^{2}$
}

Received: 2 November 2015/Revised: 18 December 2016/Accepted: 3 April 2017

(C) The Author(s) 2017. This article is an open access publication

\begin{abstract}
Many design industries have design process models specific to their discipline. However, there is no design process model specific to the design of sports equipment. Sports equipment is highly user-centred to improve the sporting performance of an athlete; therefore, it is anticipated that the outcome of this study will have an impact on the design discipline as a whole, as lessons can be learnt from the user-centred nature of sports design. This paper reports on a practical study and followed a rigorous, iterative approach of development and evaluation. The paper presents the development and validation of a sports design process model with the outcome of a sports design process model that is reflective of sports design practice in industry.
\end{abstract}

Keywords Sports design · Design process · User involvement

Nicky Wilson

nicky.wilson.2013@uni.strath.ac.uk

Avril Thomson

avril.thomson@strath.ac.uk

Philip Riches

philip.riches@strath.ac.uk

1 Department of Design, Manufacture and Engineering Management, University of Strathclyde, 75 Montrose Street, Glasgow G1 1XJ, UK

2 Department of Biomedical Engineering, Wolfson Building, University of Strathclyde, Glasgow G1 1XJ, UK

\section{Introduction}

Despite the large number of research projects across a range of design disciplines, there is no evidence of the design process of sports equipment having been studied and formally captured in a process model in its own right. This is surprising on two counts. One, with the increasing demand in sport to continually improve sporting performance, it would be expected that more interest would have been taken into the process of sports design and two, from the increase in awareness of user centred design in recent years, it is expected that lessons could be transferrable between user-focused disciplines.

This research builds on previous work (Wilson et al. 2015) that investigated the similarities and differences between the design processes of six sports equipment and six consumer product companies. The paper concluded that although the core stages of the design process did not vary between companies, key differences were observed in the level of user involvement throughout the process. The user was involved extensively throughout the sports design process, which viewed the user and the product as a system. Sports equipment (on its own a purely mechanical system) can be viewed as interacting with the athlete as a biomechanical system (Stefanyshyn and Wannop 2015), where the equipment should act as an extension of the athlete's body (Muller 2011). The study (Wilson et al. 2015) also found that the sports design process was highly iterative within process stages, although iterations between stages were reported to be rare. This was in contrast to the product companies interviewed, which reported multiple iterations between process stages as standard practice.

Based on these findings, it is apparent that key differences exist between the sports equipment and consumer product design processes. This paper aims to develop and 
present the first design process model specific to the design and development of sports equipment. The paper reports on a practical study that is reflective of industry practice, with practicing sports designers involved in the development and validation of the sports design process model. The contribution to knowledge is a descriptive sports design process model, which has been rigorously validated to ensure that it provides an accurate representation of the process currently followed by sports designers in practice. Within this paper, the term "sports design" refers to the design discipline where designers "work with the sports equipment manufacturers to develop technology that is user-friendly and will support and improve the performance of the athlete" (Jenkins et al. 2010). The term "sports designers" refers to the designers of any sports equipment, with "sports equipment" defined as the artefact used by an athlete to practice sport.

It is difficult to define "sport" as what is perceived as sport by society is evolving (Muller 2011). The scope of this study relates to the companies involved in the research, and as such, determines the generalisability of the sports design process model presented here to the field of sports design as a whole. This research is applicable to the design of the following types of sports equipment: outdoor and leisure (including extreme sports such as skiing), athletics, racquet and ball sports (including tennis, golf, football, hockey, etc.). This takes into account both elite and recreational sports, as well as disability sports, where they align with the scope of the study. Companies that were involved in the research are reflective of these areas and included companies that design products such as tennis racquets, golf clubs, running shoes, football boots, ski's. Within these areas, the athlete must interact directly with the sports equipment to enable sporting performance. While many of the companies involved in this research focus on elite and professional athletes, many of the products produced by those companies are also available to the mass consumer market.

\section{The need for a sports design process model}

Sports design is a young and evolving discipline of engineering (Medwell et al. 2011) that is recognised as an emerging cross-disciplinary industrial and academic field (Wodehouse et al. 2011). The sports industry itself is growing, with Forbes predicting an increase in the size of the sports market from $\$ 60.4$ billion in 2014 to $\$ 73.5$ billion in 2019 (Forbes 2015). Sports equipment must work together with the athlete to improve sporting performance- "the main objective of sports technology for competitive sports is to increase performance" (Muller 2011). This is in agreement with Krueger et al. (2006) who states that an improvement in athlete performance is required in high level sports to gain a competitive advantage. Both studies highlight that usability is a key factor in sports equipment design.

Sports designers who design this sports equipment possess a range of skills that are not fully covered in traditional engineering subjects (Medwell et al. 2011), including biomechanical testing and dealing directly with coaches and athletes (Medwell et al. 2012). This skill set equips sports designers with a deeper understanding of user and performance requirements and it is anticipated that this approach will be captured through modelling the sports design process. Given this unique skill set and the increasing complexity and specialisation of high quality sports equipment (Krueger et al. 2006), there is a surprising lack of a design process model specific to the discipline of sports design. A recent paper (Wilson et al. 2015) presents the results of a study comparing sport and product design practice in industry. Findings from the paper indicate that the sports design process can be characterised by continual user involvement throughout the design process with the designer directly engaged with the user, in addition to iterations within design process stages rather than between.

To identify existing published work into the sports design process, an extensive literature review was conducted using combinations of key words to search internet databases and identified key papers relating to the research. Key words used in the search included 'sports design', 'sports engineering', 'design processes', 'process models', 'sports equipment design' used in a variety of combinations. The search resulted in 626 results once filters were applied within the data bases. This was reduced to 25 articles once duplicates were removed and titles and key words were read to identify potentially relevant papers. Of the 25 articles, 9 were found to be of direct relevance to the research. The reference lists for relevant papers identified additional literature and this process was repeated to a point of saturation. Key journals and conferences to the sports design field (for example: the Journal of Sports Engineering) were also searched to identify existing work into the sports design process. No date was used for exclusion criteria as the core purpose of the search was to identify the existence of a sports design process model, regardless of publication date. In addition to searching for work specific to sports design practice, the literature reviewed a range of design process models across various design disciplines.

The literature review identified no published model of the sports design process as a whole and found little published work relating to the sports design process specifically. This is in agreement with previous work, where Medwell et al. (2012) and Muller (2011) both identified a lack of literature on the subject, although some papers (e.g., 
Pialot and Legardeur 2008) have discussed aspects of the design process in relation to certain types of sports equipment. Despite a lack of a process model for the sports design process as a whole, the literature review highlighted several models related to aspects of sports equipment design. Muller (2011) developed a prescriptive model (Fig. 1) that communicates behavioural aspects within the context of sports technology and is intended for use in clarifying input parameters for new design work and for the evaluation and comparison of existing products. Krueger et al. (2006) developed a model that considered the athlete, activity, equipment and environment (Fig. 2) and is aimed

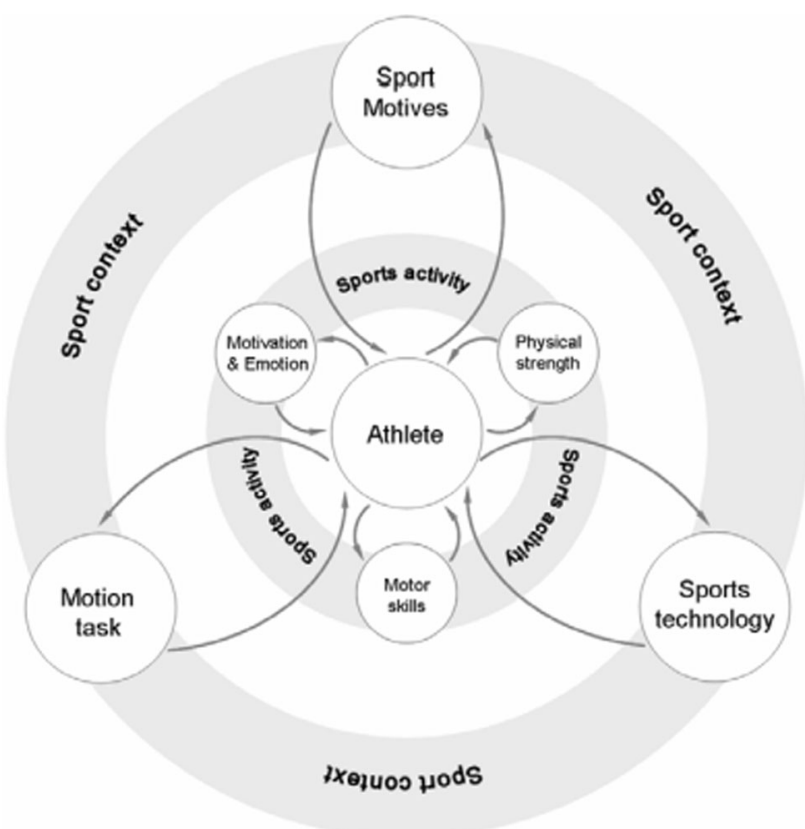

Fig. 1 Sports model communicates behavioural aspects in the context of sports technology Source: Muller (2011) at supporting the design process of sports equipment. Both models are intended to support designers at specific stages of the design process-for Muller (2011) the model is intended to aid task clarification, determination of functions and design of modules, while the model presented by Krueger et al. (2006) assists designers of performance orientated sports equipment-however, neither model captures the sports design process as a whole.

As a result of the literature review, there was no model identified in the published literature that captures the complete sports design process. However, it is noted that sports designers have a unique set of skills that differentiates them. It is therefore concluded that there is a need for a sports design process model that communicates the specific characteristics of the design process that differentiate it from other design disciplines.

\subsection{Existing design processes}

The design process is defined as "a rigorous, cyclical process of enquiry and creativity... consisting of a series of methods that are put together to suit the nature of each design project" (Best 2006). The design process should highlight the methods and activities that are critical to companies and how they interact (Unger and Eppinger 2011). However, it is difficult for designers to describe their design process due to variation between projects and because many processes are followed unconsciously (Bruseberg and McDonagh-Philp 2002) making standardisation difficult. Design processes can be descriptive (representing practice) or prescriptive (an improved, systematic sequence of activities) (Gericke and Blessing 2011). The outcome of this study will be a descriptive model of the sports design process used in industry and will be a generic model of sports design practice, rather than specific to
Fig. 2 Sports model illustrating interaction between athlete, activity, environment and equipment Source: Krueger et al. (2006)

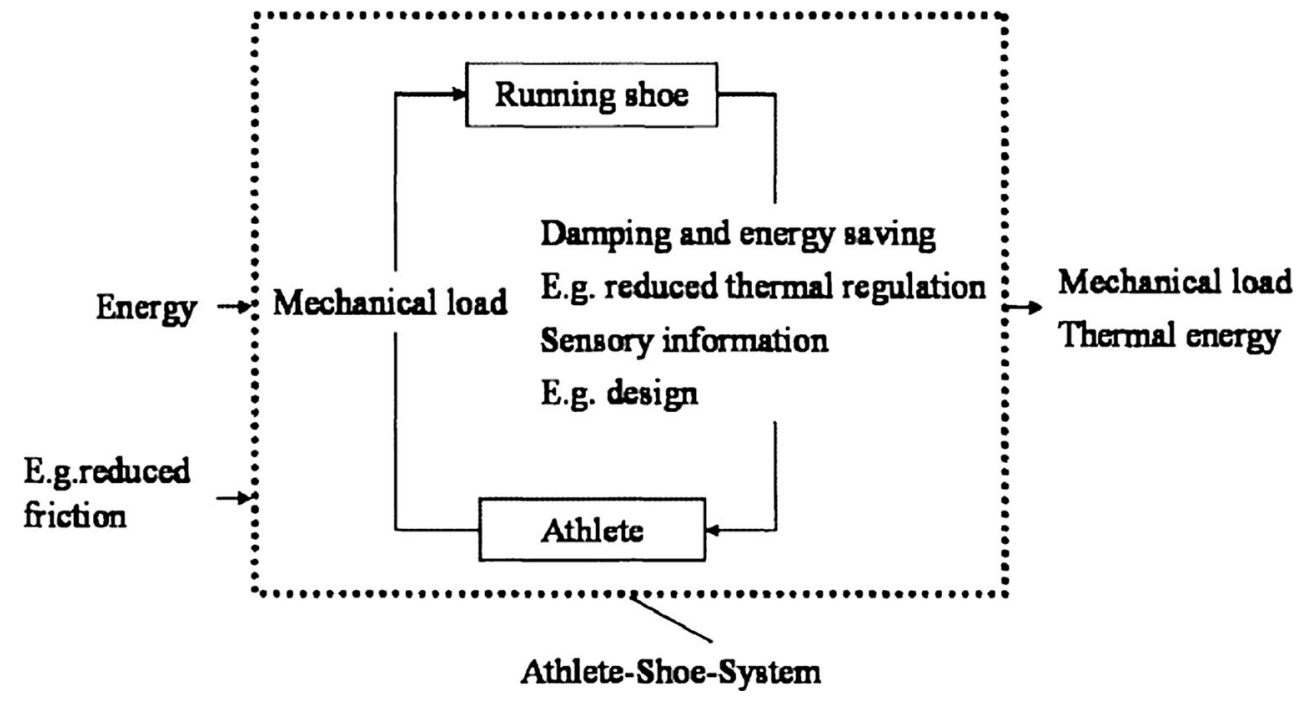


Table 1 Overview of theoretical design processes (adapted from Howard et al. 2008)

\begin{tabular}{|c|c|c|c|c|c|c|c|}
\hline & $\begin{array}{l}\text { Problem } \\
\text { definition }\end{array}$ & $\begin{array}{l}\text { Formation of the } \\
\text { brief }\end{array}$ & $\begin{array}{l}\text { Conceptual } \\
\text { design }\end{array}$ & $\begin{array}{l}\text { Embodiment } \\
\text { design }\end{array}$ & Detail design & Implementation & \\
\hline Cross & \multicolumn{2}{|l|}{ Exploration } & Generation & \multicolumn{2}{|l|}{ Evaluation } & \multicolumn{2}{|l|}{ Communication } \\
\hline $\begin{array}{l}\text { Boehm Spiral } \\
\text { Model }\end{array}$ & \multicolumn{2}{|c|}{ Task identification } & $\begin{array}{l}\text { Evaluate } \\
\text { alternatives }\end{array}$ & \multicolumn{2}{|c|}{$\begin{array}{l}\text { Evolutionary/incremental } \\
\text { development }\end{array}$} & Review & Implementation \\
\hline $\begin{array}{l}\text { Ship design } \\
\text { spiral }\end{array}$ & \multicolumn{3}{|c|}{ Requirements plan } & Product design & $\begin{array}{c}\text { Detailed } \\
\text { design }\end{array}$ & \multicolumn{2}{|l|}{ Implementation } \\
\hline $\begin{array}{l}\text { Double } \\
\text { diamond }\end{array}$ & Discover & Define & Develop & & & \multicolumn{2}{|l|}{ Deliver } \\
\hline French & Need & $\begin{array}{l}\text { Analysis of } \\
\text { problem }\end{array}$ & $\begin{array}{l}\text { Conceptual } \\
\text { design }\end{array}$ & $\begin{array}{l}\text { Embodiment of } \\
\text { schemes }\end{array}$ & Detailing & & \\
\hline Pahl and Beitz & Planning & $\begin{array}{l}\text { Clarification of the } \\
\text { task }\end{array}$ & $\begin{array}{l}\text { Conceptual } \\
\text { design }\end{array}$ & $\begin{array}{l}\text { Embodiment } \\
\text { design }\end{array}$ & Detail design & & \\
\hline Pugh & Market & Specification & $\begin{array}{r}\text { Concept } \\
\text { design }\end{array}$ & \multicolumn{2}{|l|}{ Detail design } & Manufacture & Sell \\
\hline Stage Gate & Discovery & $\begin{array}{l}\text { Scoping/build } \\
\text { business case }\end{array}$ & Development & & $\begin{array}{l}\text { Validation and } \\
\text { testing }\end{array}$ & Launch & $\begin{array}{l}\text { Post-launch } \\
\text { review }\end{array}$ \\
\hline $\begin{array}{l}\text { Ulrich and } \\
\text { Eppinger }\end{array}$ & & Strategic planning & $\begin{array}{l}\text { Concept } \\
\text { development }\end{array}$ & $\begin{array}{l}\text { System-level } \\
\text { design }\end{array}$ & Detail design & $\begin{array}{l}\text { Testing and } \\
\text { refinement }\end{array}$ & $\begin{array}{l}\text { Production } \\
\text { ramp up }\end{array}$ \\
\hline Waterfall & Requirements & & & $\begin{array}{l}\text { High level } \\
\text { design }\end{array}$ & $\begin{array}{r}\text { Detailed } \\
\text { design }\end{array}$ & \multicolumn{2}{|c|}{$\begin{array}{l}\text { Implementation/ } \\
\text { verification/maintenance }\end{array}$} \\
\hline
\end{tabular}

individual companies. As stated by Gericke and Blessing (2012), many design processes are based on older process representations of previous models. The focus of this study is to describe current industry practice of sports designers and therefore does not have foundations in older models.

There are many published design process models, as illustrated in Table 1. Although this list is by no means exhaustive, it provides an overview of the core process stages of several published design process models. Although not all are product design processes [for example: Boehm's (1988) design spiral for software design] all have applications across a range of design disciplines (Costa et al. 2015).

A major difference between the models presented here is the linear vs spiral nature of the model. According to Cross and Roozenburg (1992), the linear model typically emphasises the stages through which the project is expected to progress, compared to the spiral models illustrating the cycle of cognitive processes the designer is expected to perform. Gericke and Blessing (2011) go further to state that models can be distinguished by the emphasis they place on design stages and activities, indicating that the characteristics of sports design practice may be reflected within its design process.

Sports design is a design discipline that has a number of key attributes that differentiate it from other design disciplines through its focus on the performance of the user and the product together. While some process models (e.g. Pugh's Model of Total Design 1991) place emphasis on user participation and awareness in the supplementary text that accompanies the process models, Maffin (1998) states that many designers only have a basic knowledge of design process models themselves and not the text that accompanies them. As many process models do not represent user integration within the model itself, underlying aspects of design processes that are not represented within the model will be lost to designers. The sports process model will capture key aspects of sports design practice in a manner that is clearly communicated to sports designers, without accompanying text.

This study focuses on the design of sports equipment, which in itself is a user-focused discipline. However, it is apparent that there is a need to improve user consideration across other design disciplines, widening the potential impact of this work. Many design industries have design processes that are specific to their requirements-e.g., the design spiral for ship design (Rawson and Tupper 2001). These models are then often used within other design disciplines-for example the design spiral, intended for ship design, has evolved and is now used in the design of aircraft and in mature product architecture (Clarkson and Hamilton 2000). Although there are other user centred design process models that exist (Ielegems et al. 2015), many of these are prescriptive. The model presented in this paper is a descriptive process model of sports design practice.

\subsection{User involvement in the design process}

User involvement is critical to aid designer understanding. However, despite much research and claims that greater 
user inclusion within the design process results in a better solution (Wilkinson and Angeli 2014), there still appears to be a lack of user involvement throughout the design process as many design activities are not user centred ( $\mathrm{Li}$ and Gunal 2012). It is often beneficial to observe users in the early stages of the design process as the way in which they interact with existing products can be used to identify problems (Kahmann 2000) and can spark creativity. User information is also a key factor in setting the constraints of a design problem (McGinley and Macredie 2011) and should be used to influence the design from an early stage.

Designers cannot rely on their own skill sets or experiences to design for the wider population (Kett and Wartzack 2015). Wilkinson and Angeli (2014) state that user experience and business opportunities can be affected by a lack of user consideration throughout the design process. Competition between products and companies is increasing with customers becoming more selective. It is essential that products satisfy user requirements to ensure companies maintain a competitive advantage, gaining entry into more lucrative markets (McGinley and Macredie 2011).

It is apparent that for sports equipment, the athlete and the product must work together to improve overall sporting performance. As stated by Medwell et al. (2012) sports designers deal directly with athletes and coaches to understand their performance requirements. This is in agreement with a study by Wilson et al. (2015), which found that sports designers engaged with the athlete throughout the entire design process. The study compared the design processes followed by six product design and six sports equipment design companies. It was found that product companies showed considerably less user involvement throughout their design process, as illustrated in Fig. 3 where shading represents instances of physical user involvement throughout the design process. Product companies reported user involvement in the early research stages and then again at the end of the process. In contrast, sports designers considered the user from the outset and continued this involvement throughout the design process. Although not shown in Fig. 3, which only illustrates physical user involvement, sports designers reported that user needs and performance factors also played a key role in decisions taken at the review stages. In contrast, product designers reported focusing more on the functionality of the product, rather than usability. The findings of the study suggest that sports design shows greater user interaction throughout the design process than traditional product design.

\section{Approach to the research}

This study followed a five-step rigorous approach of development and validation, as illustrated in Fig. 4. This approach ensured that the outcome was a descriptive process model, representative of sports design practice and in a format that clearly communicated key attributes of the sports design process. All developments of the model are based solely on feedback gained from sports designers at each stage. The study was completed over a period of 15 months and involved the participation of commercially practicing sports designers to ensure the final model was descriptive of industry practice. Designers involved in the study came from companies specialising in the design of

KEY: Stages of user involvement within the design process:
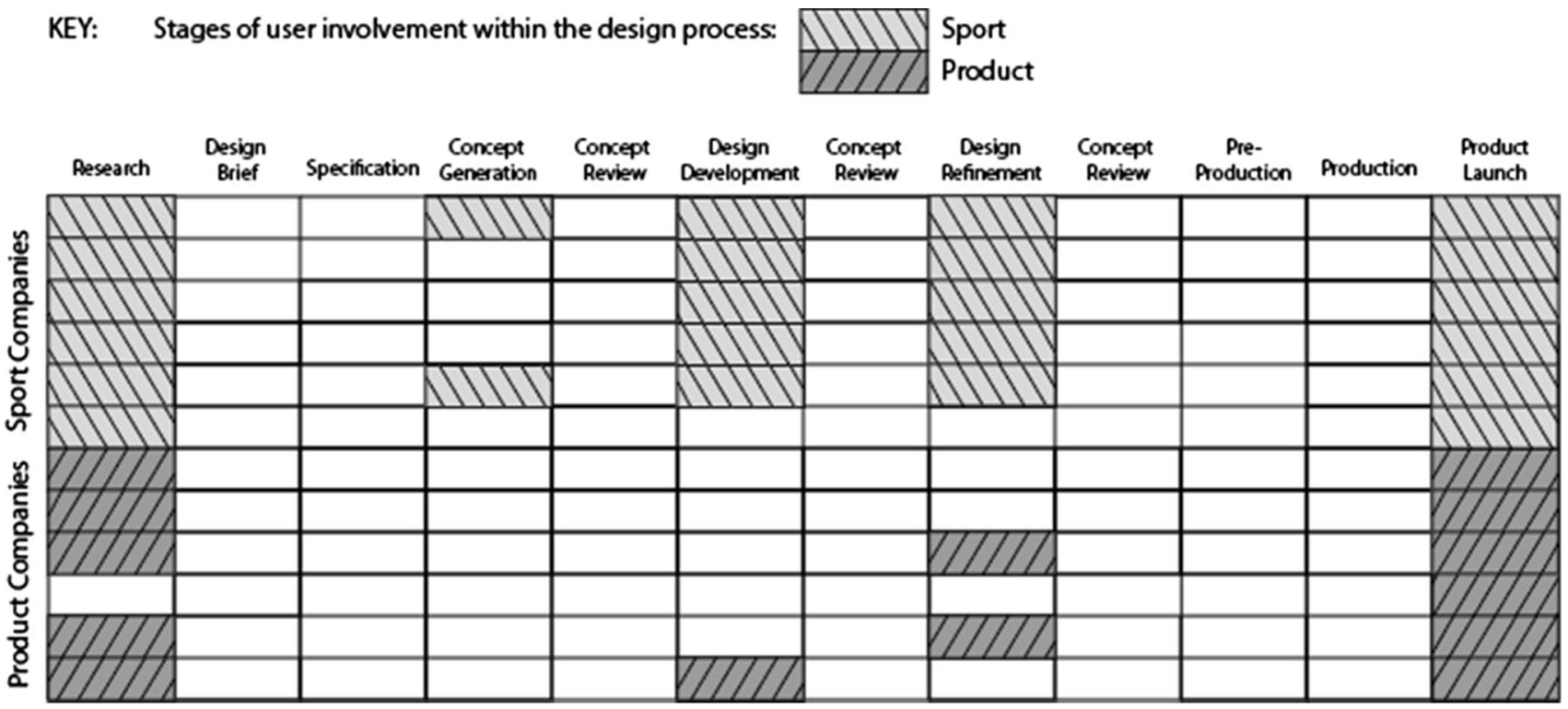

Fig. 3 User involvement throughout the design process—-sport v product companies Source: Wilson et al. (2015) 
Fig. 4 Research methodology

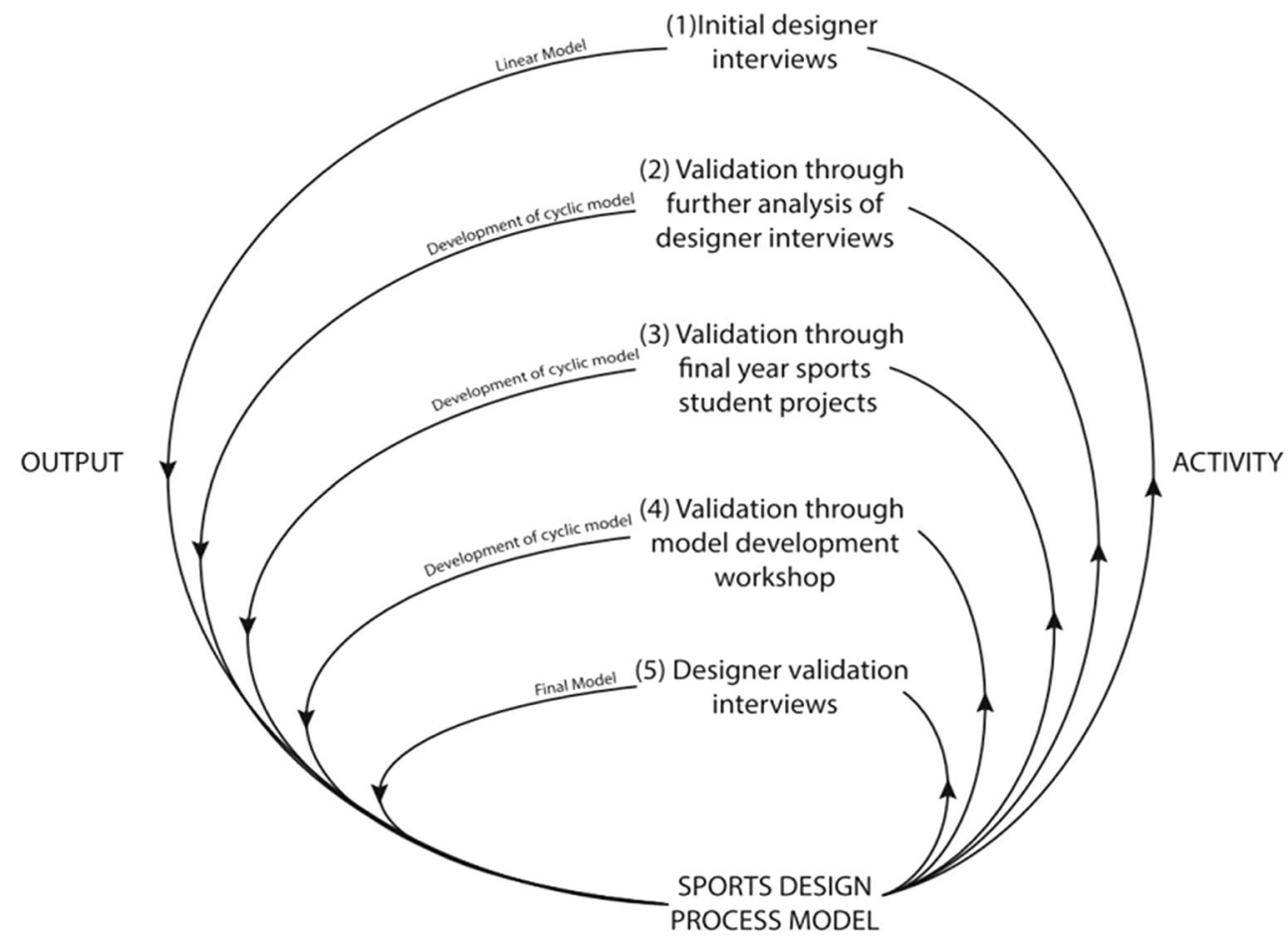

various sporting products including golf clubs, tennis racquets, running shoes and football boots, targeted at improving sporting performance within the elite and recreational sporting markets. The academic community were also engaged in the validation process to ensure the model was correctly communicated and interpreted.

Step one involved the completion of an initial set of semi-structured interviews with six sports equipment designers - three from large, multi-national companies and three from small companies. Company size was determined based on guidelines from the Companies Act (2006), which defines a small company as, "meeting two of the following: annual turnover of $£ 6.5$ million or less, the balance sheet total must be $£ 3.26$ million or less, the average number of employees must be 50 or fewer". A large company is defined as larger than the criteria listed for a medium-size company: "an annual turnover or $£ 25.9$ million or less and an average of 250 employees or fewer" (Companies Act 2006). Products designed by sports companies included golf clubs, tennis racquets, running shoes and football boots. All companies designed products focusing on athlete performance, with the majority of products targeted at the elite athlete, but also available to the mass consumer market.

All those interviewed were senior designers within their company's design and development departments with several years' experience and a detailed knowledge of their design process due to on-going involvement in implementing that process. Designers were recruited for the study through past industry connections and carefully selected based on their experience. Interviews were conducted, where possible in person (two were conducted via Skype) and lasted around $40 \mathrm{~min}$. The interviews were analysed using a general inductive approach (Thomas 2006), consisting of an iterative process of coding and refinement to identify core themes, which will be discussed in more detail in the following sections of this paper. The output of those interviews included a linear model of the sports design process drawn by each of the designers.

The designer interviews were re-analysed (step two of Fig. 4) using the same general inductive approach to validate the linear model and it was concluded that this initial linear representation did not communicate strongly enough many of the characteristics reported by the sports designers that differentiated the sports design approach from other design disciplines. The further analysis of the designer interviews resulted in a cyclic model, which better described industry practice.

The cyclic model was validated through analysis of final year university student sports design projects (step three of Fig. 4), with the aim of establishing similarities and differences between the processes recorded by students and those reported by designers in industry. Students documented all aspects of their work through extensive reports and folios, allowing a comparison of the processes followed as students reported in detail on the sequence of activities and methods that were undertaken. Results were analysed and presented in a manner similar to that of the company interviews to allow a comparison of results. This validated of the model, ensuring that appropriate questions 
had been asked in the development of the descriptive model.

A workshop was carried out with sports designers (step four of Fig. 4) to further refine the representation of the cyclic model. This process was used to evaluate the model from a designer perspective and ensure that the outcome was a representative of how sports designers viewed their design process. The workshop was recorded and physical notes made by participants were collected, in addition to questionnaires completed by participants to provide feedback on the model.

A final set of semi-structured interviews (step five of Fig. 4) were conducted with industry practising sports designers to validate the model. The interviews were again analysed using a general inductive approach (Thomas 2006). Participants were sports designers selected based on the same criteria as those involved in stage 1 of Fig. 4-of the five designers interviewed, two were involved in the initial interviews and three were new to the research. Minor refinements were made to the model as a result of recommendations made. The final outcome is a validated descriptive model of sports design practice in industry.

\section{Development of the linear sports design process model}

Designers were questioned on their design process itself, activities undertaken and user involvement within the process and were asked to produce a visual representation of their design process during the interview. Further information was added to those process diagrams by the researcher after analysis of interview transcripts. This ensured that key attributes of the process discussed by the designers were captured within the graphical representation of the process. Those final design processes were then returned to the designers for validation.

As a result of coding the interview transcripts, the key activities undertaken at each stage of the sports design process were identified. These were used to identify the core stages of the sports design process and allow standardisation of the terminology used to refer to those stages. Figure 5 illustrates the core stages of the design processes for the six sports companies interviewed. Shading is used to represent stages present in the design process of each company, while darker hatching is used to represent iterations within a stage.

None of the companies reported following a specific sports design process-all followed a generic product design process that had developed over time to suit the needs of the company and the project. The three large sports companies followed almost identical design processes. All included the same core stages and worked to similar time scales of $1 \frac{1}{2}-2$ years. All included design review stages within the process at points of key decisionmaking. One small sports company showed an unusual process, although it was concluded this was due to the nature of the product, which was assembled from existing component parts. The remaining small companies showed similar processes to the large companies, with the exception of second and third design reviews and pre-production stages.

Following analysis of the interviews, it was concluded that the sports design process was highly user centred with the user integrated throughout the design process. User involvement in the early stages (research and conceptual design) was typically through interviews, focus groups and observations, while in the later stages (design development and refinement), user testing involved more focused performance testing. The users involved in the process were often elite athletes, performing at the professional and semi-professional level of their sport. User considerations heavily influenced the design review process between process stages. One company quoted in reference to elite athlete input in the early stages of the process: "he's got specific requirements that he likes... we try and build that into the product" (Large Company A). It was acknowledged by sports designers that the athlete had a high level

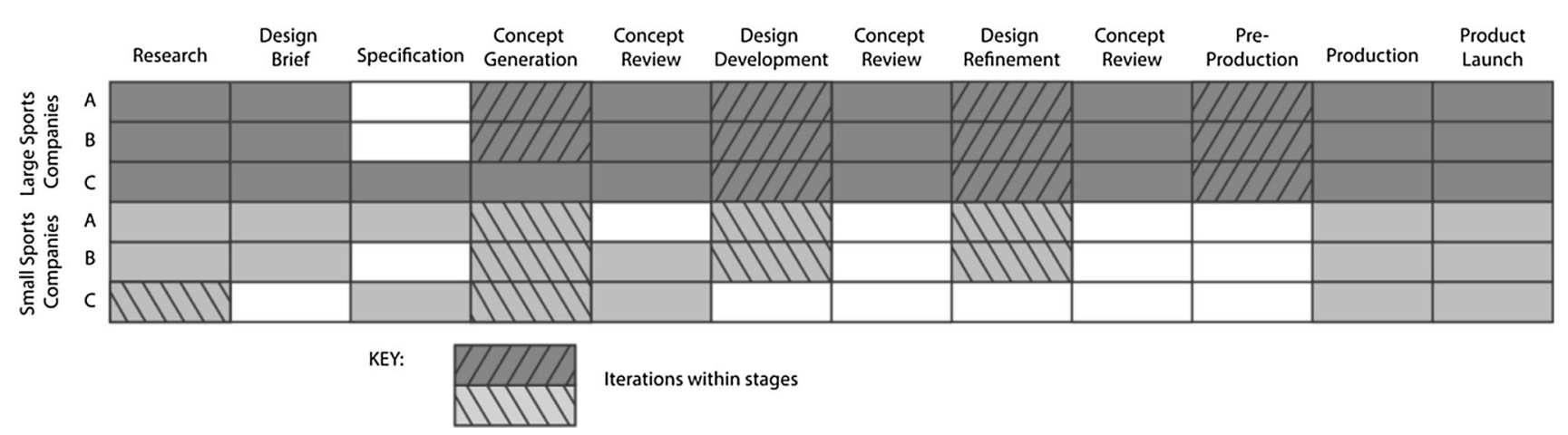

Fig. 5 Standardised design processes for six sports companies 
of understanding of the performance requirements of their sport and it was in the interest of the designer to consult continuously with them throughout the design process to ensure that their needs were met. Sports designers focused on the performance aspect of the product, ensuring the product and the user work together to achieve optimal sporting performance. One company reported- “our target is to improve the perceived performance of the product" (Large Company B), highlighting that the emphasis was not just on the technical output of testing but on the subjective feedback from the athlete. This resulted in a highly iterative process of user and product testing throughout the process, with prototyping occurring as early as possible.

The results of the interviews showed that sports companies did not report iterations between stages (no stages missed or back-tracking)_companies reported typically two to three iterations within the stages themselves. In contrast, Wilson et al. (2015) found that product companies reported it was standard practice for iterations and re-work, resulting in backwards iterations within the design process. For the sports companies, iterations were reportedly due to repetitive prototyping, user testing and evaluation to ensure the product met the performance requirements of the athlete. All companies reported carrying out extensive testing throughout the design development and refinement stages to assess the performance requirements of the equipment, with methods of testing varying between companies.

An initial linear model of the sports design process (Fig. 6) was generated based on the standardised individual company processes shown in Fig. 5. The model was generated based on the following rationale:

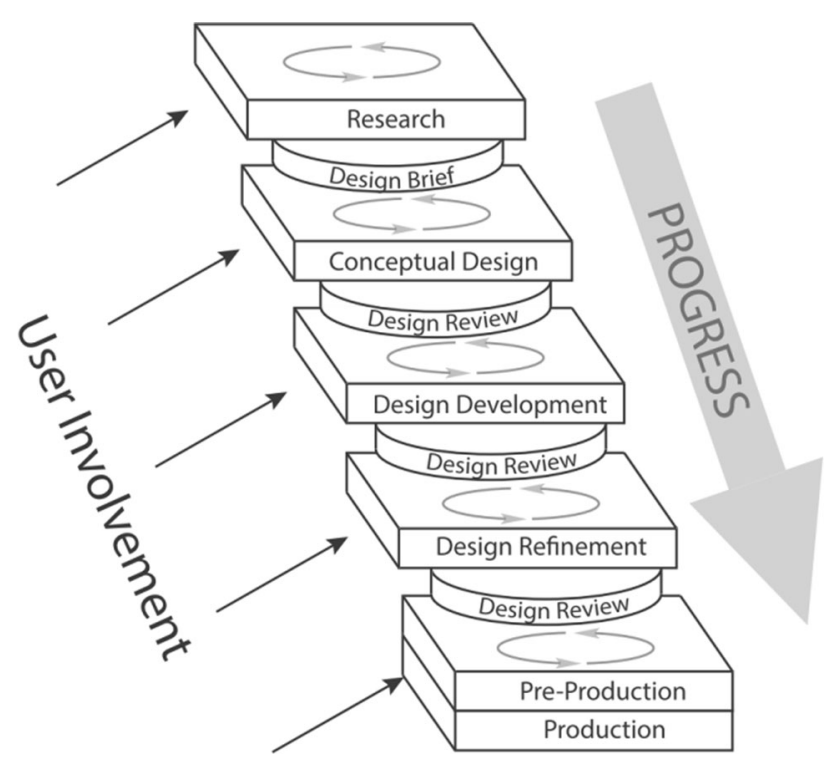

Fig. 6 Initial linear representation of the sports design process
- All companies produced some form of design brief or specification. The information included in both showed little variation between companies, therefore both stages were combined.

- All large sports companies followed design review stages after design development and design refinement. Although smaller companies did not formalise this stage, a decision-making stage was reported towards the end of the design stages.

- Iterations within stages were a feature of the sports design process. Designers reported multiple repetitions of the conceptual design, design development and design refinement stages. However, iterations between process stages were rare, resulting in a linear representation of the process with iterations within stages.

- A linear representation was adopted as a result of designers choosing to represent their process in this manner. Although no direction was given regarding how to represent the design process, all designers chose to illustrate the process linearly. It is assumed that this is due to the format that many traditional design processes are represented in, therefore is a format many designers are familiar with.

The model (shown in Fig. 6) was based on standardisation of the process terminology and the conclusions drawn above. Square platforms represent the core stages of the design process and highlight the iterations within these stages. A design brief and design review stages provide a link between core stages.

Whilst there are some similarities between the linear process shown in Fig. 6 and other conventional product design process models in terms of core stages and representation, there are key differences between the sports model shown here and other representations of the design process discussed earlier in this paper, including the emphasis placed on user integration and the iterative nature within process stages. This initial linear representation was evaluated through further analysis of the designer interviews and it was concluded that the key findings from the interviews (shown at stage one in Fig. 4) - the integration of the user throughout the process and the iterative nature within process stages-were not represented and communicated strongly enough through this linear model.

\section{Development of the cyclic sports design process model}

Further analysis of designer interview transcripts (stage two in the research process shown in Fig. 4) was carried out to validate the categories and themes found during the original analysis. This process confirmed conclusions 
drawn previously that the sports design process is both highly user-focused with the user integrated throughout the process and a high level of iterations within process stages. A cyclic representation of the sports design process was generated to capture and describe the iterative nature of the process communicated by the designers-shown in Fig. 7 . The cyclical representation, allowing for iterations within a stage and movement between stages towards a central goal, graphically illustrates these findings. The cyclic process allows designers to repeat stages if the appropriate solution is not found or to move on to the next stage in sequence, but does not allow movement back to previous stages.

The re-analysis of the interview transcripts confirmed initial findings that user integration was key throughout the sports design process. Designers interviewed (at stage one of Fig. 4) stated that "the customer is king" (small company C) and "you don't touch the product alone-you touch the system that you and the product build together" (large company B), emphasising the importance sports companies place on improving the overall performance of the product and user together. Emphasis on meeting user needs and performance requirements, were recurring themes within the interview transcripts for all companiesthere was no evidence within the transcripts of a stage within the process for any company where the needs of the user were not discussed in relation to design and development decisions. The horizontal lines passing through each stage of the process model in Fig. 7 represent this integration of the user and the design review activities that must be completed at all stages of the process, ensuring that the user is fully integrated throughout the process.

The central point of the process model has been termed "product launch" as this model represents the design and development process. Analysis of the interviews showed few instances where designers had discussed the production process without prompting from the researcher. None of the designers were able to provide an accurate breakdown of what occurred during the production stages of the process as they had little involvement in it, therefore these were not included in the model.

\subsection{Validation with final year student projects}

The cyclic model, constructed as a result of the initial designer interviews, was validated against six final year sports design student university projects (stage three of Fig. 4). As the model is intended to be descriptive of industry practice, changes were not made to the model as a result of this validation process. Students were considered to be representative of the designer population as all were final year students, with projects conducted over a

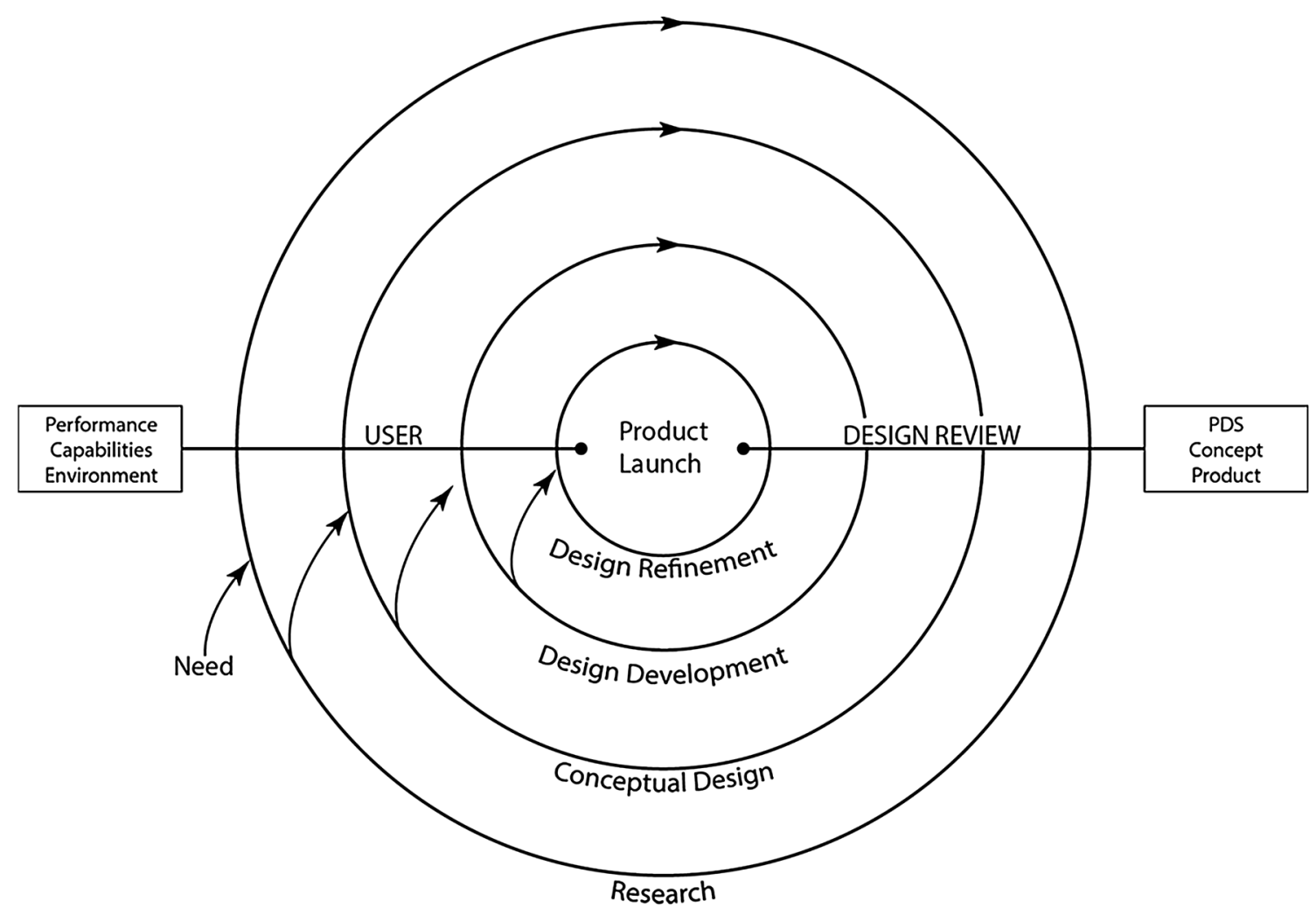

Fig. 7 Further development of the sports design process (initial cyclical model) 
9 month period and contributing towards $25 \%$ of final year grades. Students within the department also had experience working on industry projects (a core part of the course) and were encouraged to undertake industrial placements, therefore had an understanding of sports design practice in industry. The projects showed the development of an innovative piece of sports equipment from the early research stages through to a finalised product (final prototypes and manufacturing drawings were produced for each project). It was found that five out of the six projects had adapted existing process models to increase emphasis on user integration in the process, with all projects stating that usability was a key design requirement. Although students were required to follow a design process and were familiar with several existing published design process models prior to the project, those that adapted existing process models reported that they did so as they felt existing models did not provide an adequate representation of the process they should follow. One project reported, "the (initial process model) did not consider the material testing and analysis protocol that would be essential to the success of the project". That project then adapted the process model to include an iterative process of analysis, testing and prototyping within stages. This was representative of five of the projects, where students felt the need to adapt existing design processes to incorporate a user centred focus into the process to allow for user needs to be identified and met. The remaining project did not adapt an existing process model, although stated the approach followed was 'user centred'. It is, therefore, apparent that students found existing process models inadequate at representing the specific needs of the sports design process.

The validation process followed a similar approach to that of standardising the original company processes - core stages and activities were identified from the student projects and the terminology for each stage was standardised. Statements made throughout the project reports were collected and grouped according to core themes. Students had documented all aspects of their projects, allowing for an indepth analysis of the processes followed without the need for further interviews. A number of similarities were observed, which validated the model (Fig. 7), developed as a result of the designer interviews:

- Similar core process stages (research, conceptual design, design development, design refinement).

- Like the sports companies, student projects showed iteration within stages rather than between-no student project reported backwards movement through the design process. Like the sports companies, iterations of development, user testing and evaluation were common for all projects.
- The user was key to all student projects, with emphasis on user involvement at all stages of the process-many of the student projects emphasised that the approach followed was user centred. User related activates included initial interviews and questionnaires, focus groups and extensive prototype testing.

- Product testing was a core part of the student projects, validating the solution in terms of improvement to performance.

A number of key differences were also observed:

- Student projects did not progress beyond the design refinement stage (although consideration was given to manufacturing processes and product promotion) due to the nature of university student projects.

- Design review stages were not formalised within the student design processes although key activities (reference back to the design specification and justification of design decisions) were recorded at the end of conceptual design, design development and design refinement that were in line with the design reviews undertaken by sports companies at the same stage in the process. It is also noted that student projects were individual and not completed as part of a design team.

- Greater emphasis was placed on the conceptual design stage in student projects, as all were new product development projects. In practice, very few projects are new product developments (Margolin 1997), with many being developments of existing products, resulting in less emphasis on conceptual design.

The adaptation of existing process models by students reiterates the need for a process model specific to the discipline of sports design as students were unable to find a process model that captured the needs of a sports design project. Changes to the sports model shown in Fig. 7 were not made as a result of analysing the student projects as the model is intended to be descriptive of sports industry practice. However, analysis of the student projects validated the cyclic model, ensuring that it was descriptive of the practice of the sports design community.

\subsection{Designer workshop}

A workshop based critique session (stage four of Fig. 4) was carried out with four sports designers to ensure the sports process model accurately described industry practice. The workshop lasted an hour and introduced participants to the linear representation of the sports design process shown in of Fig. 6 and the cyclic representation shown in Fig. 7. The aim of the workshop was to ensure the model was descriptive of sports design practice and that this model would be correctly interpreted by designers. The 
models shown in Figs. 6 and 7 were based on the researchers' interpretation of the interview results, therefore the workshop provided a basis to validate the model and improve the model representation further based on designer's own experiences. A group discussion followed a structured approach, with discussion questions including aspects of the model that were reflective of general industry practice and ease of interpretation of the models. The workshop was recorded and analysed, with comments on the models classified according to core themes and feedback questionnaires that were completed by all participants. The remainder of this section details the conclusions reached as a result of the workshop, in addition to examples of the data collected. The following conclusions were reached:

1. The linear model was simple to follow and would allow for good project structure. Emphasis on iteration, user consideration and performance was lost.

2. The cyclic model was visually attractive and best illustrated the iterative nature of the sports design process. Whilst it was apparent that user consideration and design review lines were central to the process, it was not clear from the lines that this was an activity to be undertaken-one designer quoted "don't use a line-an activity box would show something has to be done".

The workshop concluded that the cyclic model was most descriptive of the process followed by sports designers in industry due to the clear emphasis on user involvement and the aesthetic appeal of the iterative shape of the process. Feedback gained from the workshop emphasised that the model should be simple and flexible, allowing designers and organisations to adapt it to suit their needs on a project to project basis. One participant stated, "emphasise the stages of the process but leave the activities flexible to the project and the designer". In the feedback questionnaires, participants were asked to rank requirements they felt were important within the model-ease of interpretation was ranked highest by three out of the four designers. However, the overall structure of the process should not be lost and the content of the model will remain unchanged. The following improvements were made to the cyclic model based on feedback from the workshop to ensure the model was representative of sports design industry practice and are illustrated in Fig. 8:

- The horizontal lines in the model were confusing. It was suggested that activity boxes should be added to the model to highlight a task should be undertaken.

- There was a lack of flow between stages of the design process, therefore stage names were moved to the top of the model to allow for a more natural flow-from top to bottom.

- It was unclear that the requirements listed next to the design review were outputs from each stage. These are now illustrated within the model as an output from the design review process.
Fig. 8 Further development of the sport design process model

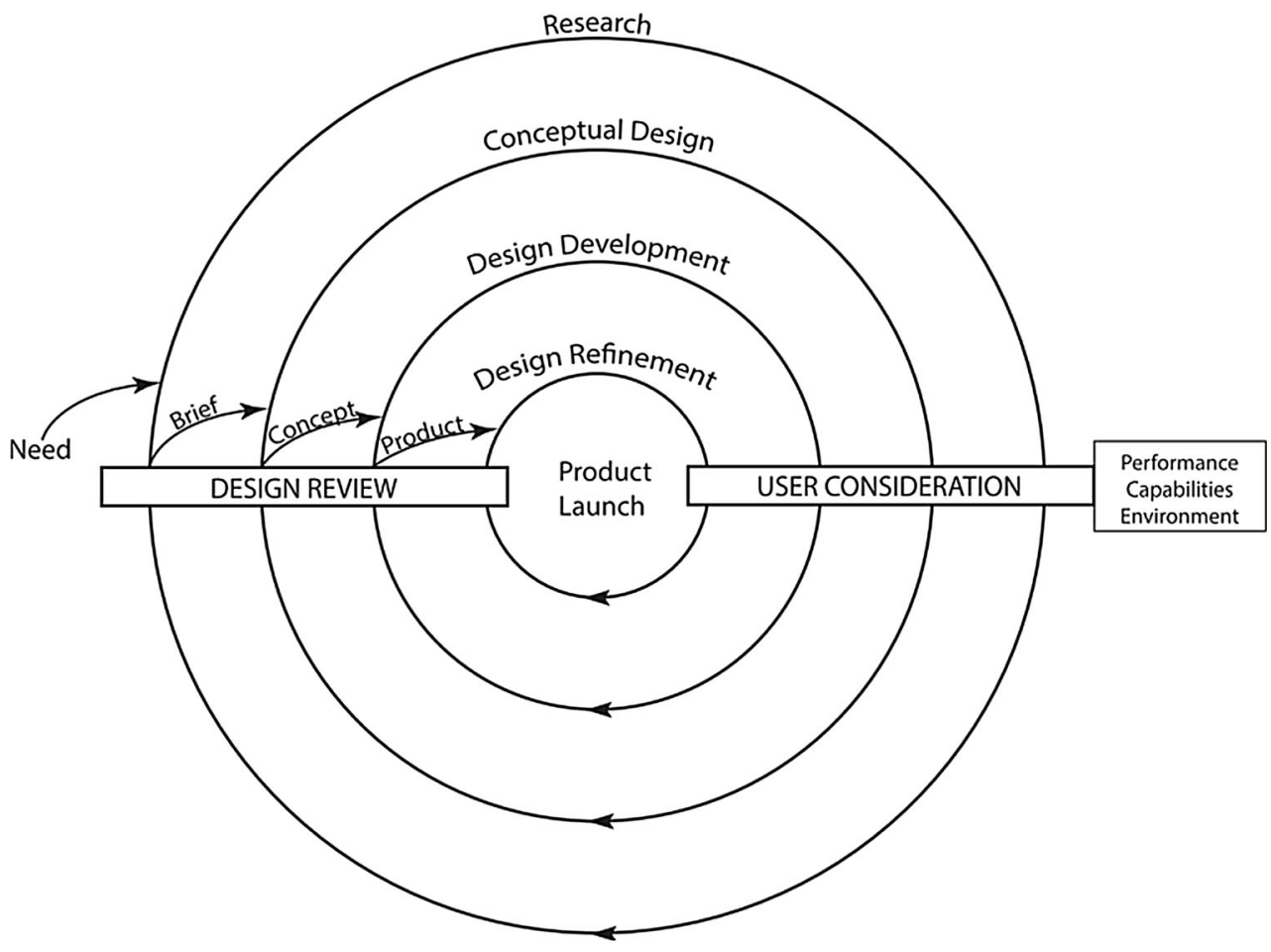




\section{Validation of the sports design process model}

A final validation was carried out to ensure the final outcome was a descriptive model, representative of sports design practice. Five sports designers were interviewed to validate the final model (stage five of Fig. 4)-from two large companies, two small and one medium. Designers were again carefully selected based on experience and position within their company. The interviews followed a semistructured approach, which provided an in-depth analysis of the process model and aimed to identify the following:

1. Did the designer understand the model?

2. Was the process representative of the designers (or company's) own practice?

3. What modifications would be needed to ensure the model is an accurate representation of industry practice?

In response to question one, designers were quoted saying, "I think it's really attractive and easy to absorb," and "I get it and instantly I was comfortable with it. I like how it just looks like it flows really well", emphasising that ease of understanding was key to the model. This positive feedback was gained from all designers following the presentation of the model, with presentation found to be a recurring theme throughout the interview transcripts. All designers could understand the model and were able to discuss the process with ease.

All designers agreed that the model was representative of their own practice. The cyclic nature of the model was representative of the nature of sports design- "we're constantly going round in circles, constantly going round the same check points, but just at different points in the process". Terminology relating to the iterative nature of the process stages came up repeatedly in relation to design activities and progress through a project. All designers thought the model had captured the sports design process, from the iterative nature of design to the emphasis on the user and the decision-making process at the review stages.

In response to how the model could be improved further, all interviewees indicated that the terminology used for "product launch" implied the design process progressed from a fully developed product at the end of design refinement straight to the launch of the product-in reality there is a full commercialisation process that is not shown within the model. The model presented here is intended to represent the design and development cycle, therefore detail on the commercialisation phase it not shown. The term "product launch" was re-named "project sign-off" indicating that the product is not in a state to be launched but design work is completed.

Designers also felt that the representation of "user consideration" shown in Fig. 8 could be interpreted as a "tick the box" activity and did not convey the high level of testing and user integration within the sports design process. One company was quoted saying: "the reality is that we're constantly going round in circles... Testing dictates the design-we make design updates based on the testing feedback", emphasising both the iterative nature of the process and the high level of user involvement and testing. The model was further modified to reflect this feedback from the sports designers regarding their everyday practice, as shown in Fig. 9. This placed more emphasis on user involvement and extensive testing within the model, showing a breakdown of the nature of user centred design methods used, from data gained from the original set of designer interviews.

Feedback from the designers indicated that additional levels of detail (such as the text next to user consideration-performance, capabilities, and environment-in Fig. 8) should not be shown as a simplified version of the model was an accurate representation of industry practice. One small company reported that it would be of great benefit to allow designers to add to these considerations over time to ensure that all potential requirements were met. However, these recommendations were not incorporated into the final model as feedback from all other companies was to keep the model simple without over complicating. One designer reported, "the more structured it would be, the less likely we would probably be to use it", due to individual project changes. This was representative of the feedback gained from the remaining four designers interviewed.

Two of the companies interviewed as part of the validation process indicated an immediate intention to use the model as a training tool within their design and development team. It was stated that the model was representative of the process currently followed and was applicable to each of the companies. Both designers commented on the benefits of adopting the model within the company to provide an overview of the company process as a whole to enable designers to understand where everyday tasks fit "within the bigger picture". Although the companies followed a similar series of activities within each project cycle, there was no formalised process used within either company at the time of the interview. It is, therefore, concluded that the model was descriptive of the sports design process and has the potential to benefit sports designers within industry by providing a simplistic overview of the sports design process as a whole.

\subsection{The sports design process model}

The final sports design process model is shown in Fig. 9. The model illustrates a cyclic process, moving round the model from one stage in the design process to the next, 
Fig. 9 Final representation of the sports design model

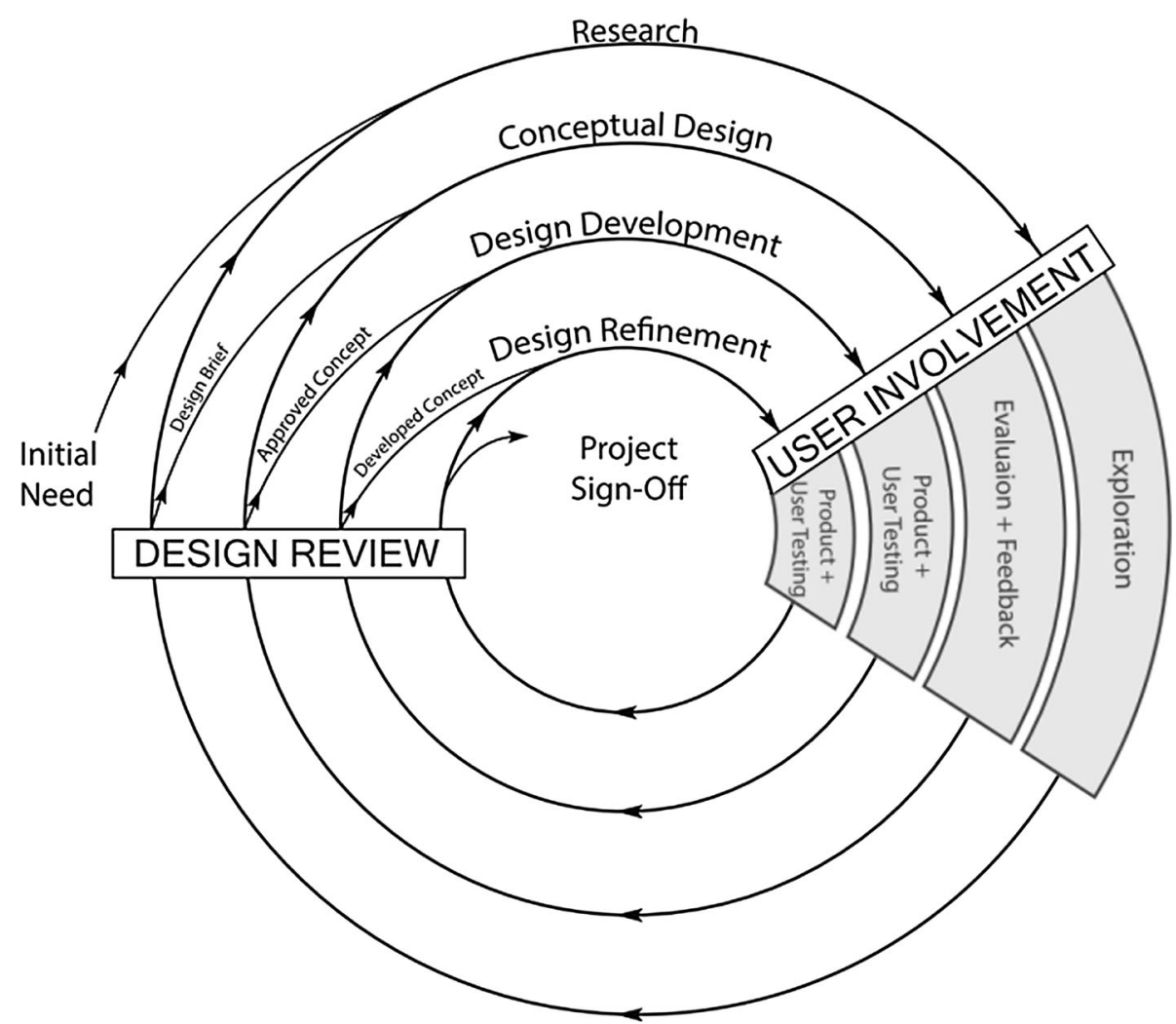

conveying the iterative nature of the sports design process within stages. As it was noted that iterations between the process stages themselves were rare, (for example, between conceptual design and design development) the model does not allow for backward iterations or the omission of stages.

There are two activity boxes that must be passed through at each stage of the design process-user involvement and design review. User involvement ensures that the needs of the user are central to each stage of the process. In sports practice, it was noted that the user themselves were involved at all stages, with the exception of conceptual design where user involvement was rare. However, at the conceptual design stage, the needs of the user were emphasised and considered when generating and evaluating concepts, with users at times involved in the evaluation of concepts. At all other stages of the process, the user was directly involved through a range of methods, ranging from evaluation and feedback of existing products and competitors in the early stages of the process, to user trials and testing in the design development and refinement stages. The review process was completed at the end of each stage to ensure that the project was on track to meet the design brief and included input from a range of stakeholders within the company.

The outcome of each stage is illustrated in the process model after the design review process. After the research stage, a specification or design brief is produced. The outcome of conceptual design was the approved concept that would be progressed through to design development, while the outcome of design development was a developed concept. At the design reviews, the outputs were assessed against the design brief in terms of performance targets and user requirements and a decision was taken to progress to the next stage of the process or repeat the previous stage.

The sports model differs from other design processes in that it is specific to the design of sports equipment. While some features of the model presented here show similarities with aspects of other process models, the sports model is unique in that it provides a visual representation of the core stages of the sports design process, the iterative nature of that process and the need for continual user involvement and validation throughout the process, which have been identified as characteristic of the sports design process. Other design disciplines have process models specific to them as discussed earlier in this paper, with differences existing between the emphasis placed on design stages and activities within the models. This highlights the demand for industry-specific design process models. This study presents the first process model to capture the characteristics of the sports design process as a whole.

\section{Conclusion}

No company involved in the research reported having a formalised representation of their design process that is published or reportedly in use. During the final validation 
interviews, designers commented that the sports model presented here was easier to understand and more applicable to sports design practice than other published design process models. The literature review produced no results in terms of an existing sports design process model and from analysis of sports design student projects, it was apparent that none found a process model that was representative of the sports design process. It is, therefore, concluded that the model presented here is the first design process model which captures the sports design process.

Although similar to many existing generic design models in the terminology used to refer to core stages of the process, there are key differences that distinguish this model. The sports design process brings together many attributes such as the emphasis placed on user integration throughout the process together with iterations only within process stages and not between stages. The cyclic representation illustrates the iterative nature of sports design within process stages, while ensuring a linear progression through the process itself, which is not illustrated within many other theoretical process models. Design review stages, although not unique to sports design practice, highlight areas of decision-making within the process, where user consideration plays a key role in decisions made. The final contribution is a descriptive process model that reflects the identified characteristics of sports design practice-a user centred and iterative process.

This study is in agreement with other literature discussed in this paper that sports design is highly user-focused, primarily due to the athlete and equipment working together to improve sporting performance. Designer involvement with the coach and athlete is also cited as characteristic to sports design. This user-focused nature of sports design practice is reflected in the sports design model, throughout the design process.

The model presented in this paper is a descriptive model and has been validated as an accurate representation of the sports design process followed in industry. As the first model to capture and describe the sports design process, it is expected that this model will be beneficial to sports designers themselves, allowing them to visualise the design process as a whole and for small companies to structure their process-as highlighted by sports designers in the final validation interviews. The sports design process model presented here therefore has the potential to improve the success of sports equipment products through improved customer satisfaction, improved safety and/or performance. It is also expected that the model will be beneficial in an academic setting in the education of undergraduate sports designers-with sports engineering courses now established in the UK, Australia, America and Europe, there is a growing need for a design process model specific to sports design. As discussed previously in this paper, there is also the potential for the design process model presented here to be of use in other user centred design disciplines.

This study followed a thorough approach of continual validation of the sports model, ensuring that the final model was both representative of sports design practice and presented in a way that was beneficial to the designers themselves. Whilst the sample size in this study could have been larger, the rigorous process of improving and validating the process model will minimise these limitations.

The work undertaken within this study does not currently apply to more diverse sporting contexts, such as motor sports, equine equipment, etc. However, there is potential for further work to examine the applicability of the model presented here to these wider areas. As an additional recommendation for future work, it is hypothesised that there is scope for the model to be used prescriptively within other areas of design practice. As the model presented here is descriptive of sports industry practice and therefore currently used by designers in industry, there is scope for it to be followed within wider product design practice. It is also anticipated that the userfocused design process model presented here could have an impact on the design discipline as a whole, in terms of emphasising the importance of user involvement, when to involve the user within the design process, the nature of user involvement at each stage of the process and can be used as a design tool, educational tool or communication tool to aid user centred design practice in other design disciplines.

Open Access This article is distributed under the terms of the Creative Commons Attribution 4.0 International License (http://crea tivecommons.org/licenses/by/4.0/), which permits unrestricted use, distribution, and reproduction in any medium, provided you give appropriate credit to the original author(s) and the source, provide a link to the Creative Commons license, and indicate if changes were made.

\section{References}

Best K (2006) Design management: managing design strategy, process and implementation. AVA, Worthing

Boehm B (1988) A spiral model of software development and enhancement. Computer 21(5):61-72

Bruseberg A, McDonagh-Philp D (2002) Focus groups to support the industrial/product designer: a review based on current literature and designer's feedback. Appl Ergon 33(1):27-38

Clarkson PJ, Hamilton JR (2000) 'Signposting', a parameter-driven task-based model of the design process. Res Eng Design $12: 18-38$

Costa DG et al (2015) Towards the next generation of design process models: a gap analysis of existing models. International Conference on Engineering Design, Milan

Companies Act (2006) Companies Act 2006 [Online]. Available at: http://www.companieshouse.gov.uk/companiesAct/implementa tions/apr2008ExemptionThreshold.shtml. Accessed 21 Nov 2014 
Cross N, Roozenburg N (1992) Modelling the design process in engineering and architecture. J Eng Des 3(4):325-337

Forbes (2015) Sports industry to reach $\$ 73.5$ billion by 2019. [Online] Available at: http://www.forbes.com/sites/darrenheitner/2015/ 10/19/sports-industry-to-reach-73-5-billion-by-2019/ \#706f4c1585. Accessed 19 Sep 2016

Gericke K, Blessing L (2011) Comparisons of design methodologies and process models across disciplines: a literature review. International Conference on Engineering Design, Kopenhagen

Gericke K, Blessing L (2012) An analysis of design process models across disciplines. Design, Dubrovnik

Howard T, Culley SJ, Dekoninck E (2008) Describing the creative design process by integration of engineering design and cognitive psychology literature. Des Stud 29:160-180

Ielegems E, Herssens J, Vanrie J (2015) A V-Model for more. An inclusive design model and supporting interaction between designer and user. International Conference on Engineering Design, Milan

Jenkins PE, Plaseied A, Khodaee M (2010) UCD sports engineering program. Proc Eng 2(2):2757-2762

Kahmann R (2000) Inclusive design: excluding users in a conscious way. In: Proceedings of the international ergonomics association/human factors and ergonomics society congress, San Diego, pp 901-904

Kett SG, Wartzack S (2015) Integration of universal design principles into early phases of product design - a case study. International Conference on Engineering Design, Milan

Krueger A, Witte K, Edelmann-Nusser J (2006) Approach of a model for the Interaction between athlete, sports equipment and environment. In: The engineering of sport 6. Springer, New York, pp 17-22

Li X, Gunal M (2012) Exploring cognitive modelling in engineering usability design. J Eng Des 23(2):77-97

Maffin D (1998) Engineering design models: context, theory and practice. J Eng Des 9(4):315-327

Margolin V (1997) Getting to know the user. Des Stud 18:227-236
McGinley C, Macredie R (2011) Towards diversity and empathy in design development. Zoontechnica J Redir Design 1(1):187-206

Medwell PR, Brooks LA, Medwell BS (2011) Analysis of the lawn bowl trajectory as a teaching tool for sports engineering: development of a graphical user-interface. Proc Eng 13:531-537

Medwell PR, Grimshaw PN, Robertson WS, Kelso RM (2012) Developing sports engineering education in Australia. Proc Eng 34:260-265

Muller M (2011) Enhancing sport-sports technology design in the context of sport motive, motion task and product feature. Technische Universitat Munchen, Munich

Pialot O, Legardeur J (2008) Management of new ideas during early design phases of innovative products in the surf industry. Eng Sport. Springer, Paris, pp 587-596

Pugh S (1991) Total design: integrated methods for successful product engineering. Addison-Wesley Publishers Ltd, Essex

Rawson KJ, Tupper EC (2001) Basic ship theory. ButterworthHeinemann, Oxford

Stefanyshyn DJ, Wannop JW (2015) Biomechanics research and sport equipment development. Sports Eng 18(4):191-202

Thomas DR (2006) General inductive approach for analysing qualitative evaluation data. Am J Eval 27(2):237-246

Unger DW, Eppinger SD (2011) Improving product development process design: a method for managing information flows, risks and iterations. J Eng Des 22(10):689-699

Wilkinson CR, Angeli AD (2014) Applying user centred and participatory design approaches to commercial product development. Des Stud 35:614-631

Wilson N, Thomson A, Riches P (2015) Can the sports design process aid the inclusive design community? International Conference on Engineering Design, Milan

Wodehouse A, Ion W, Mair G (2011) Sports engineering: developing an integrated, cross-disciplinary engineering design degree. In: Proceedings of E\&PDE 2011, the 13th international conference on engineering and product design education, London 